\title{
Modelling and Simulation of Train Brake System in Low Adhesion Conditions
}

\author{
Hamid Alturbeh ${ }^{1 *}$, Julian Stow ${ }^{1}$, Gareth Tucker ${ }^{1}$ and Alan Lawton ${ }^{2}$ \\ 1 Institute of Railway Research, University of Huddersfield, Huddersfield HD1 3DH, UK \\ 2 Rail Delivery Group Ltd, 2nd Floor, 200 Aldersgate Street, London EC1A 4HDUK \\ *h.alturbeh@hud.ac.uk
}

\begin{abstract}
This paper describes the current version of the Low Adhesion Braking Dynamic Optimisation for Rolling Stock (LABRADOR) simulation tool that can predict the train brake system performance and support decision-making in the design and optimisation of the braking system including WSP, sanders, and the blending and control of friction and dynamic brakes in low adhesion conditions. The model has been developed in MATLAB/SIMULINK and is intended to mimic the braking performance of both older and newer generations of multiple unit passenger trains. LABRADOR models have been initially validated by comparing simulation results for a single car train (Class 153) and two car train (Class 158) in dry conditions with experimental tests, for tare and crush laden vehicles.
\end{abstract}

This project is supported by RSSB and a technical steering group composed of railway braking experts, suppliers and train operators and manufacturers.

Keywords: Train brake system; Low adhesion; Wheel Slide Protection WSP; Leaves on the line

\section{Introduction}

Low adhesion in the wheel-rail interface can cause both safety and performance issues. In braking it can lead to station overruns and signals passed at danger (SPADs) and in traction it can lead to costly delays. Low adhesion can result from a number of causes including wet-rail, leaves, oil, etc. [1]. Modern rolling stock braking under low adhesion uses a combination of wheel slide protection (WSP) and sanding systems to increase adhesion in the wheel-rail contact in an attempt to avoid wheel damage and/or flats and to minimise braking distance.

Over the years, research by British Rail Research, other organisations [2] [3] and more recently RSSB [4] [5] have contributed to a better understanding of the low adhesion phenomena. Other studies have focused on the modelling of train braking systems [6]; however, long train slide events do still occur and there can be significant disruption to train services during the 'leaf fall season'. There is an opportunity to further understand, and even improve the braking performance of trains by using 
the ability of modern simulation software to model the complex interdependence of brake system components in the overall behaviour of the brake system.

The aim of LABRADOR project is to develop simulation software capable of modelling the behaviour of modern multiple unit passenger trains braking under normal and low adhesion conditions. The model includes the complex interdependence of brake system components and their effects on the overall behaviour of the brake system. It is modular and allows easy specification of vehicle, bogie and wheelset subsystems. Within the wheelset subsystem WSP, sander, contact patch conditions and temperature and adhesion subsystems exist. Figure 1 illustrates the functions within the LABRADOR simulation tool.

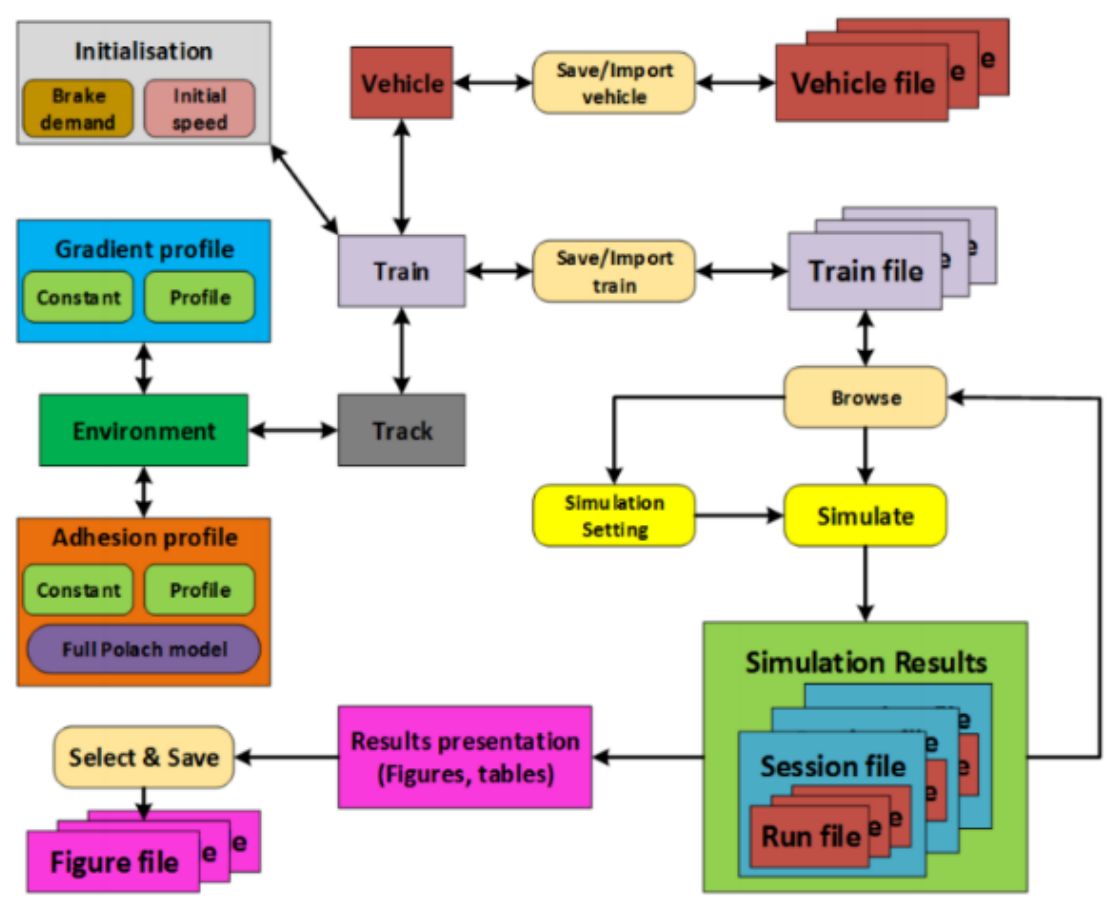

\section{LABRADOR Architecture}

Figure 1 Main LABRADOR model functions

The LABRADOR model is built based on discussed modular structure in MATLAB/Simulink. The software presents four train models; single car, two, three, and four cars train models. Each of these models is assembled from a set of modules that simulate the behaviour of discrete functions within the braking system of a train. Some modules simulate physical features that can be found on each vehicles. For example, the WSP module, mechanical behaviour of wheelsets and the influence of sand on adhesion. Some modules simulate control functions such as the brake blending controller.

The outer layer of the model, the environment layer, provide the inputs to a train module; initial speed and brake demand, adhesion and gradient etc. The train module contains one, two, three, or four functionally identical vehicle modules, each vehicle module contains a number of functionally 
identical wheelset modules. Each module type is functionally identical and provides the easiest way to exploit the duplicated systems within real, long trains. For example, changing the characteristics of WSP system for every vehicle in a 4-car train will involve a change to just the WSP module that is replicated many times within the model structure for a long train. Each wheelset module contains: one dynamic brake module; one WSP and friction brake module (WSP\&FB); one sander module; and one wheel module that contains a contact patch module.

The following sections describe the LABRADOR train models and the modules that make up the train models.

\subsection{Environment layer}

The environment layer is the top layer of the model which:

1. Provides the external data required by the train module.

2. Allows the operator to set initial conditions for train position, train speed and drivers brake demand.

3. Passes initial condition information to the train module.

4. Takes data from the contact patch modules on the adhesion behind the wheelset to update the adhesion map.

5. Provides data to the contact patch modules on incoming adhesion for each wheelset.

6. Provides gradient information to allow calculation of gravitational forces.

\subsection{Train module}

The train module consists of up to four vehicles and is the module that interacts with the environment layer as shown in Figure 2.

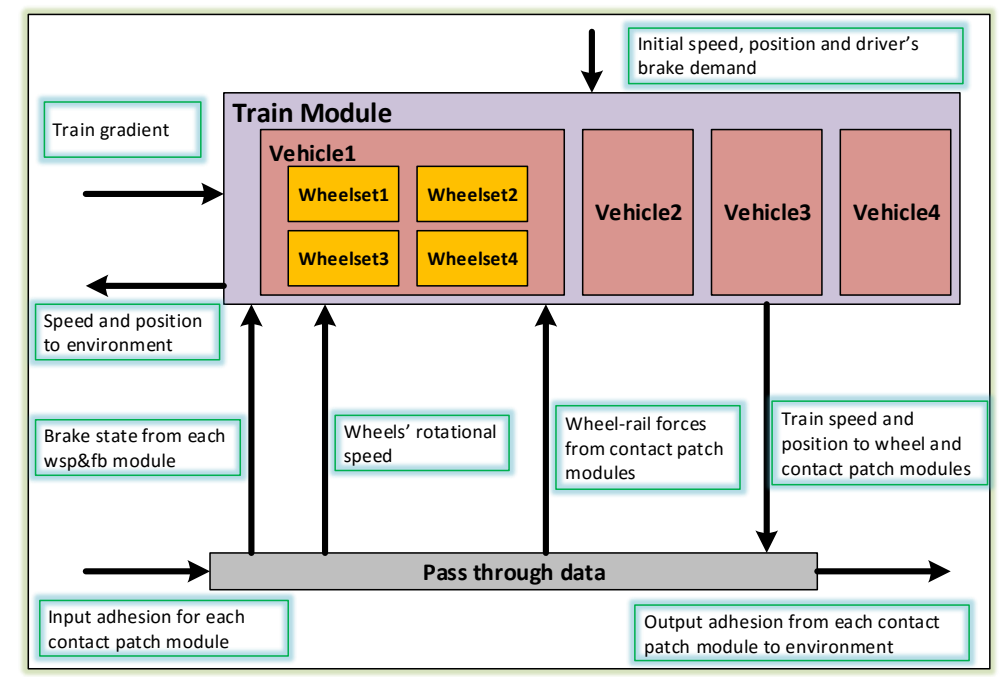

Figure 2 Train module interaction with the environment layer 
The train module:

- Calculates the drag forces as a consequence of train speed and train gravitational forces using gradient data from environment.

- Computes train acceleration, speed and position as a consequence of the drag, gravitational and wheel-rail forces applied to the train.

- Allocates drivers brake demand, from the environment, between each vehicle, according to the state of brake equipment on the vehicle (dynamic brake isolation, WSP activity etc.) and on the make-up of the vehicles (is dynamic braking available on all vehicles, etc..).

\subsection{Vehicle module}

A vehicle module contains four wheelsets modules. Figure 3 shows the vehicle module diagram interacting with the train module. The vehicle module:

- Allocates vehicle brake demand as a combination of friction brake demand and dynamic brake demand to each wheelset, depending on the state of the vehicle's brake equipment

- Calculates the load transfer due to train acceleration, wheel-rail forces and track gradient.

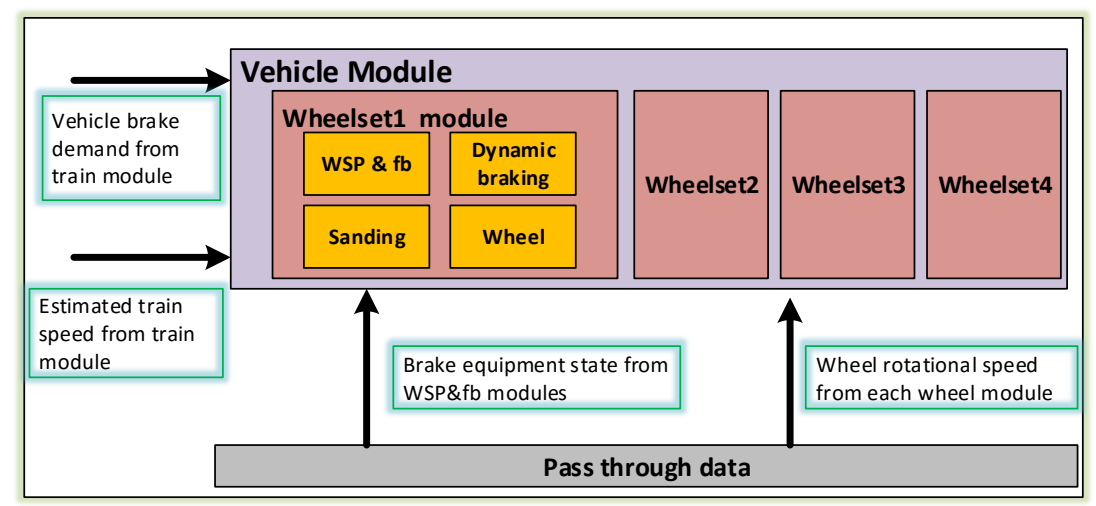

Figure 3 Vehicle module

\subsection{Wheelset module}

The wheelset module groups a number of discrete functions as shown in Figure 4 that are: dynamic brake module; WSP and friction brake module (WSP\&FB); sanding control module; rotating wheelset module (wheel), within which is found the contact patch module. These functions are contained within the wheelset module because their actions are exclusively centred on one individual wheelset. The wheelset module has no specific function; it exists to contain the modules listed above and to receive certain data from the vehicle module, such as friction brake demand, dynamic brake demand, and train/vehicle and pass it to its inner modules. 


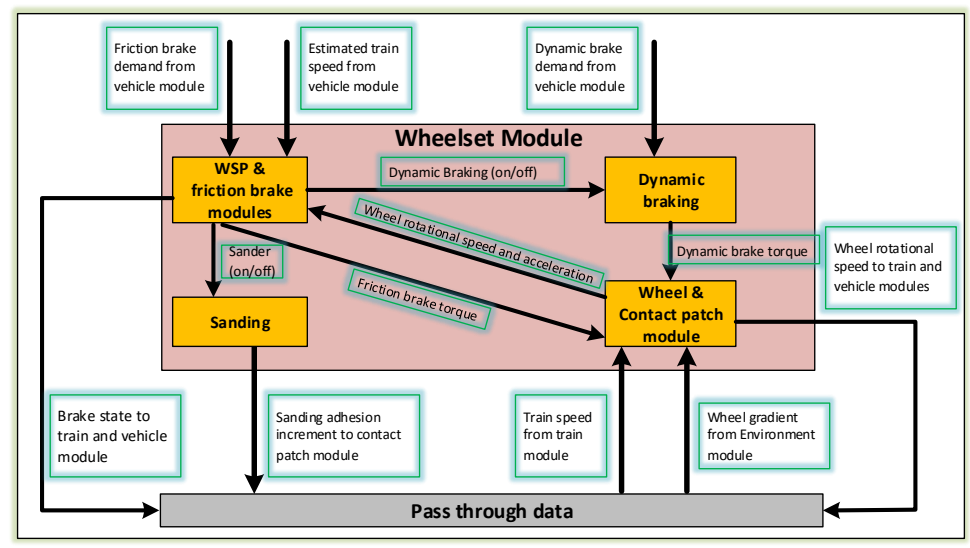

Figure 4 Wheelset module

\subsection{Contact patch module}

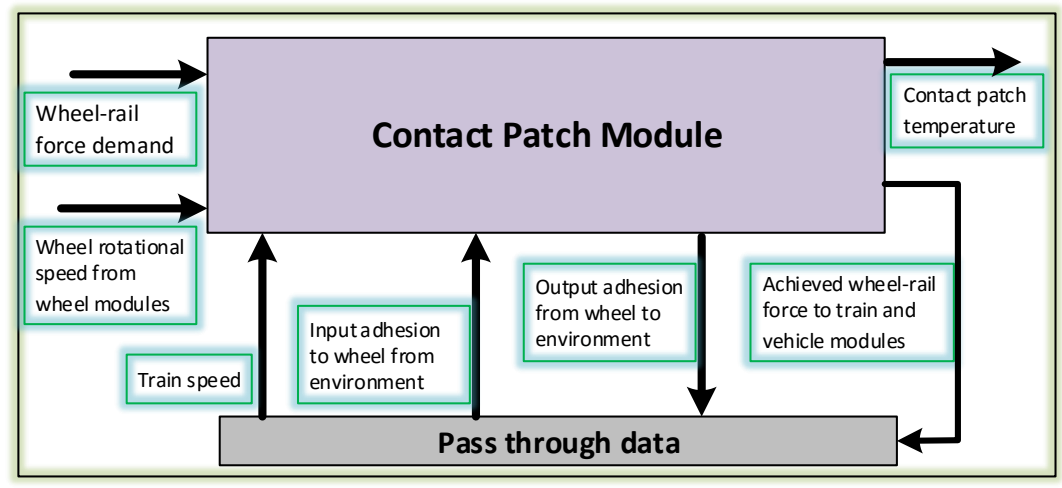

Figure 5 Contact patch module

Figure 5 shows the contact patch module, which calculates the force in the contact patch and wheel slide as a function of wheelset rotational speed, train speed, adhesion at the contact patch and the force demand on the wheel-rail contact point; calculates the output adhesion; and computes the contact patch temperature as a consequence of adhesion, normal load and actual wheel slide.

\subsection{Dynamic brake module}

The dynamic brake module is located in the wheelset module as it can be seen in Figure 4. If enabled, the dynamic brake module produces a torque on the wheelset. This brake can be disabled if wheel slide is excessive; dynamic brake torque is then zero until the train stops. The dynamic brake torque is proportional to the dynamic brake demand, and there is negligible delay between changes in dynamic brake demand and dynamic brake torque.

\subsection{Wheel slide protection $\&$ friction brake module.}

The wheel slide protection and friction brake module (WSP\&FB) is also placed in the wheelset module (see Figure 4). The activities of the WSP and friction brake are closely linked, hence, they are modelled in one module. 
The (WSP\&FB) module controls braking and sanding as a consequence of wheel slide (wS):

- Receives wheel rotational acceleration and speed from the wheel module.

- Calculates wheel slide using the actual wheelset rotational speed, wheel radius and the chosen train speed.

- Controls friction brake torque taking into consideration delays in the pneumatic system.

- Activates wheelset sanding and isolates the dynamic brake, depending on wheel slide.

- Describes the state of the brake equipment (dynamic brake enabled/disabled, friction brake on/off, sanding on/off) to the vehicle module for use in setting brake demands

Control features for braking and sanding are:

- If $w s$ exceeds $L_{1}$ for a period of time $T_{1}$ then dynamic brake is isolated.

- If $w s$ exceeds $L_{2}$ for a period of time $T 2$ then the sander module applies sand.

- If $w s$ is less than $L_{3}$ then, subject to air flow delays, friction brake torque is proportional to friction brake demand, assuming perfect frictional behaviour in the disc brake.

- If $w S$ is greater than $L_{4}$ for a period of time $T_{4}$ then, subject to air flow delays, friction brake torque is set to zero.

Where $L_{1}, L_{2}, L_{3}, L_{4}, T_{1}, T_{2}, T_{4}$ are predefined values.

\subsection{Sander module}

Sand is applied to the wheel-rail contact patch when wheel slide exceeds a certain level. The WSP\&FB module monitors wheel slide and signals to the sander module to increase adhesion, subject to a time lag. The sander module tells the contact patch module that input adhesion is increased.

\subsection{Wheel module}

The wheel module is also placed in the wheelset module as shown in Figure 4. This module models the rotational behaviour of the wheelset, depending on the dynamic and friction brake torques, the wheel load and the contact patch behaviour. The wheel modules:

- Calculate drag force for the wheelset.

- Calculate gravitational force for the wheelset

- Calculate the force demand on the wheel-rail contact point.

- Relate gravitational force, drag force, friction brake torque and dynamic brake torque (the force demand on the contact point) and available wheel-rail force to calculate wheel rotational acceleration and speed 


\section{Detailed Description of Train Braking Model}

\subsection{General description}

Any train braking model should quantify two main quantities and their associated derivatives:

\section{The train, vehicle and wheelset positions:}

By defining $x(t)$ as the train position at a particular time $t$ (in $\mathrm{m}$ ) and by defining $x_{v}(t)$ as the longitudinal position for each vehicle and defining $x_{v j}(t)$ for each wheelset in each vehicle at a particular time $t$, where $v=1,2,3,4$ is the vehicle index, and $j=1,2,3,4$ represents the wheel index. The train position is assumed to be equal to position of the first wheelset at the first vehicle, i.e. $x(t)=$ $x_{11}(t)$. The vehicles' positions $x_{v}(t)$ are the position of the first wheelset in that vehicle which can be directly defined from the train position by the following:

$$
x_{v}(t)=x(t)+\left(V_{n o}-\mathbf{1}\right)\left(V_{l}+V_{s}\right)
$$

Where $V_{n o}$ is the vehicle number $V_{l}$ is vehicle length and $V_{S}$ is the vehicle spacing.

The wheelsets' position $x_{v j}(t)$ are directly defined from the vehicle position $x_{v}(t)$ as follows:

$$
\begin{gathered}
x_{v 1(t)}=x_{v}(t) \\
x_{v 2}(t)=x_{v}(t)+W_{s} \\
x_{v 3}(t)=x_{v}(t)+B_{s} \\
x_{v 4}(t)=x_{v}(t)+W_{s}+B_{s}
\end{gathered}
$$

where $W_{S}$ and $B_{S}$ are the wheelset and the bogie spacing. The geometric centre of the vehicle is also defined as:

$$
x_{v G}(t)=x_{v}(t)+\frac{1}{2}\left(W_{s}+B_{s}\right)
$$

for calculating the effect of track gradient $\left(i=i\left(x_{v G}(t)\right)\right)$.

\section{Wheelset rotations:}

By defining $\theta_{v j}(t)$ as the wheelset rotation for vehicle $v$ wheelset $j$ at a particular time $t$ (in rad);

Figure 6 provides a schematic representation of the first vehicle with the longitudinal and rotational degrees of freedom $\left(x_{v}(t), \theta_{v 1}(t), \theta_{v 2}(t), \theta_{v 3}(t)\right.$ and $\left.\theta_{v 4}(t)\right)$ and some longitudinal dimensions (bogie and wheelset spacing $-B_{S}$ and $W_{S}$, and vehicle length $-V_{l}$ ) 


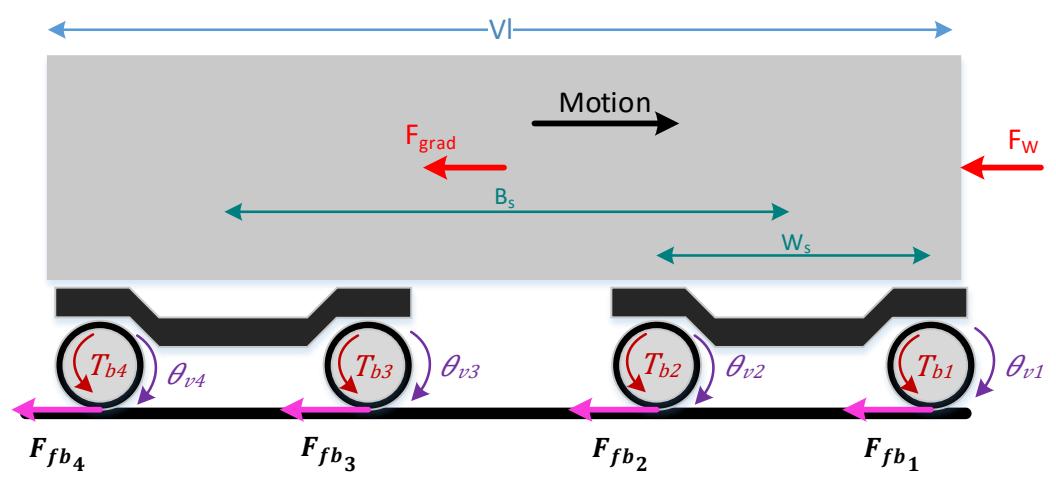

Figure 6 Vehicle diagram representing the degrees of freedom and some longitudinal dimensions.

\subsection{Equations of motion}

The degrees of freedom $x(t)$ and $\theta_{v j}(t)$ are computed through numerical integration using as boundary conditions: known initial speeds $\dot{x}_{v}(t=0)=\dot{x}_{0}$ for the vehicle and $\dot{\theta}_{v j}(t=0)=\dot{x}_{0} / R$ for all wheelsets. The following longitudinal and rotational equations are defined to conduct numerical integration.

\subsubsection{Longitudinal dynamics}

For simplicity a single vehicle model is considered in this section. Three different longitudinal forces are applied to the Vehicle:

1. The wheel-rail forces due to friction in the contact between the wheel and the rail $\left(F_{f b}(t)\right.$ for all wheelsets $j=1,2,3,4)$;

2. The train drag forces $\left(F_{w}(t)\right)$;

3. The horizontal component of the weight due to the track gradient $\left(F_{\text {grad }}(t)\right)$.

Equation 7 sums all the applied forces and divides them by the vehicle mass $(M)$ to compute the longitudinal vehicle acceleration $(\ddot{x}(t))$.

$$
\ddot{x}(t)=\frac{1}{M}\left(-F_{f b_{1}}(t)-F_{f b_{2}}(t)-F_{f b_{3}}(t)-F_{f b_{4}}(t)-F_{w}(t)-F_{g r a d}(t)\right)
$$

\subsubsection{Rotational dynamics}

Two torques are applied in each wheelset $j$ :

1. The torque due to the wheel-rail force $F_{f b_{j}}(t)$ applied in the contact between the wheel and the rail with a moment arm equal to the $\operatorname{Radius}(R)$;

2. The braking torque $T_{b_{j}}(t)$; 
Equation 8 sums all the applied torques and divides them by the wheelset rotational inertia $(J)$ to compute the wheelset rotational acceleration $(\ddot{\theta}(t))$.

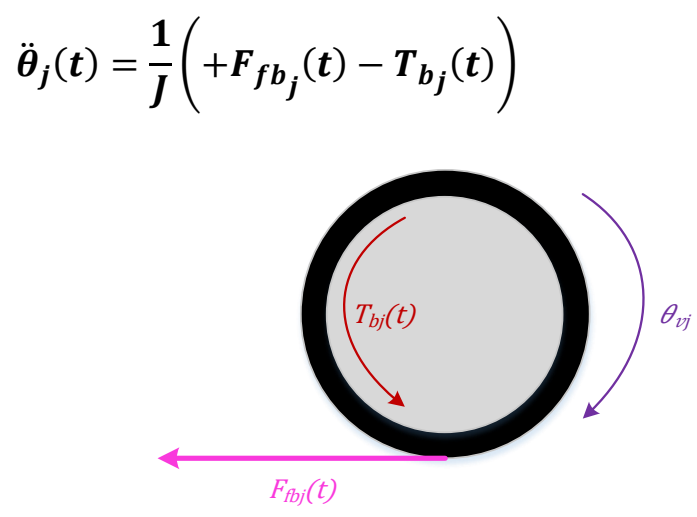

Figure 7 Wheelset diagram representing the torques applied to each wheelset

Figure 7 provides a schematic representation of the torques applied to each wheelset $\left(F_{f b}(t) . R\right.$ and $\left.T_{b_{j}}(t)\right)$. The wheel-rail force is calculated in the adhesion model which will be discussed in the following section.

\subsection{Adhesion model}

The adhesion model is based on a method developed by Polach [7] for calculation of creep forces in multi-body simulation. The Polach model is based on a theoretical model for longitudinal and lateral creep assuming a coefficient characterising the contact shear stiffness. The magnitude of the resultant creep force $F$ is obtained by integrating the shear stress distribution over the contact surface. The creep force components $F_{x}, F_{y}$ are assumed to be proportional to the longitudinal and lateral creepages. The contact area is assumed to be constant elliptical shape with half-axes $a, b$ and normal stress distribution according to Hertz. Figure 8 shows the distribution of the tangential stress $\tau$. 


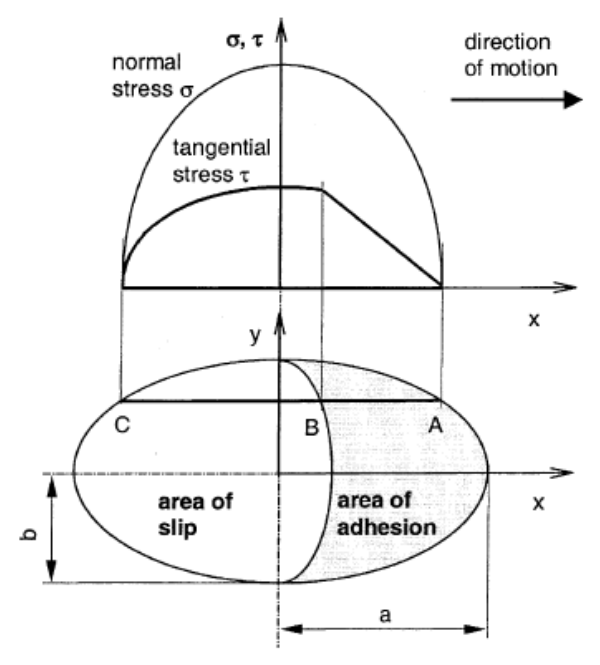

Figure 8 Distribution of normal and tangential stresses in the wheel-rail contact [7]

The maximum value of tangential stress at any arbitrary point is given by:

$$
\tau_{\max }=\mu \sigma
$$

Where $\sigma$ is the normal stress and $\mu$ is the coefficient of friction. The friction coefficient depends on the slip velocity where the friction coefficient decreases with increasing slip (creep) velocity between wheel and rail. The following equation expresses the variable friction coefficient:

$$
\mu=\mu_{0}\left[(1-A) e^{-B w}+A\right]
$$

Where $\omega$ is the total creep (slip) velocity, $B\left[s . \mathrm{m}^{-1}\right]$ is the coefficient of exponential friction decrease, and $A$ is the ratio friction coefficients given by:

$$
\boldsymbol{A}=\frac{\boldsymbol{\mu}_{\infty}}{\boldsymbol{\mu}_{\mathbf{0}}}
$$

Where $\mu_{\infty}$ is the friction coefficient at infinite slip velocity and $\mu_{0}$ is the maximum friction coefficient The tangential creep force (without spin) is given as follows:

$$
F=\frac{2 Q \mu}{\pi}\left(\frac{\varepsilon}{1+\varepsilon^{2}}+\operatorname{atan}(\varepsilon)\right)
$$

Where $Q$ is the load [N] and $\varepsilon$ is the gradient of the tangential stress in the area of adhesion given by:

$$
\varepsilon=\frac{2 C \pi a^{2} b}{3 Q \mu} s
$$


Where $a$ and $b$ are the semi-axes of the contact ellipse in longitudinal and lateral direction respectively and $C\left[\mathrm{Nm}^{3}\right]$ is the proportionality coefficient characterising the contact shear stiffness which can be derived from Kalker's linear theory [8] . For the longitudinal direction:

$$
\varepsilon_{x}=\frac{G \pi a b c_{11}}{4 Q \mu} s_{x}
$$

Where $G$ is Shear module ( $G=8.4 \times 10^{10}$ for steel), $c_{11}$ is coefficient from Kalker's linear theory, and $s_{x}$ is the longitudinal component of the total creep $s$ :

$$
\begin{gathered}
s=\sqrt{s_{x}^{2}+s_{y}^{2}} \\
s_{i}=\frac{w_{i}}{V} ; i=x, y
\end{gathered}
$$

The forces $F_{x}, F_{y}$ in longitudinal and lateral directions are:

$$
F_{i}=F \frac{s_{i}}{s} ; i=x, y
$$

and the adhesion coefficients:

$$
f_{i}=\frac{F_{i}}{Q} ; i=x, y
$$

The lateral components are neglected in the LABRADOR model. However, this model cannot describe the creep force model for various conditions of wheel-rail contact (i.e. dry, wet, and contaminated conditions). Polach has proposed an extended version of the previous model. The extended model allows creep force model to be adapt the for various conditions of wheel-rail contact according to experimental data. The extended Polach model has been incorporated in LABRADOR.

The extended Polach model for creep forces for wet, contaminated or dry rail is a combination of dry and wet frictions. This combination can be understood by observing the distribution of the area of adhesion and the area of slip over the wheel-real contact patch at different creep values at different conditions. For example, the area of adhesion extends to the greater part of the contact area for small creep values which is the case in dry friction. However, for large creep values, there is slip in the main part of the contact area. Thus, the effect of the interfacial layer of water, pollution or contaminants increases. Consequently, the stiffness of the anisotropic surface layer decreases and, as a result of this, the creep force-creep function reduces its gradient significantly. Polach has used different reduction factors $k_{A}$ in the area of adhesion and $k_{S}$ in the area of slip to model these conditions. So the extended Polach model is achieved by modifying Equation 12 to be as follows: 


$$
F=\frac{2 Q \mu}{\pi}\left(\frac{k_{A} \varepsilon}{1+\left(k_{A} \varepsilon\right)^{2}}+\operatorname{atan}\left(k_{S} \varepsilon\right)\right), \quad k_{S} \leq k_{A} \leq 1
$$

It can be seen that the extended Polach model given by Equation 19 contains two terms; the first one related to the area of adhesion and the second to the area of slip.

\subsection{External forces model}

Two external forces that are considered during braking:

1. Frictional and aerodynamic drag forces.

2. The horizontal component of train weight due to the track gradient.

\subsubsection{Drag forces}

The Davis equation is used to calculate train drag forces as a second order polynomial of train speed [9].

$$
F_{w}(t)=A+B \cdot \dot{x}(t)+C \cdot(\dot{x}(t))^{2}
$$

Equation 20 gives an empirical expression depending on the vehicle speed $(\dot{x}(t))$ and coefficients $A, B$ and $C$. Coefficients $A, B$ and $C$ for different trains have been estimated based on expressions developed by [10], and [11]. The mass-related coefficient of mechanical resistance $A[N]$ is given by:

$$
A=6.4 M_{T}+8 M_{P}[N]
$$

Where $M_{P}[t]$ is the total mass of power cars and $M_{T}[t]$ is the total mass of trailers.

Viscous mass-related coefficient of mechanical resistance $B\left[N\right.$. s. $\left.m^{-1}\right]$ is:

$$
B=0.18 T_{M}+N_{T}+0.005 N_{P} . P W
$$

Where $T_{M}[t]$ is the total train mass, $N_{T}$ is number of trailer cars, $N_{P}$ is number of power cars, and $P W[M W]$ is the train power. And coefficient of aerodynamic resistance $C\left[\frac{N . s^{2}}{m^{2}}\right]$ is:

$$
\begin{gathered}
C=10^{-3}\left(612.5 \frac{D_{h}}{D_{t}} S+1.97 \text { Peri. } T_{L}+2 \text { Peri. } I V_{g a p}\left(N_{T}+N_{P}-1\right)\right. \\
\left.+206.1 B_{\text {drag }} . N_{B o g}+256.6 N_{P n t}\right)
\end{gathered}
$$

Where $D_{h}$ is head drag coefficient, $D_{t}$ is tail drag coefficient, $S\left[\mathrm{~m}^{2}\right]$ is cross-sectional area, Peri $[\mathrm{m}]$ perimeter, $T_{L}[m]$ train length, $I V_{\text {gap }}[m]$ inter-vehicle gap, $B_{\text {drag }}$ bogie drag coefficient, $N_{B o g}$ number of bogies, and $N_{P n t}$ number of pantographs. 
Due to the track gradient, the weight of the vehicle may have a horizontal component in the longitudinal direction contributing to acceleration on a falling gradient or braking of the train on a rising one.

$$
F_{\text {grad }}(t)=M \cdot g \cdot i(t)
$$

Equation 24 gives the expression for the horizontal component of the weight $(M . g)$ due to the track gradient $i(t)$. If it is a horizontally straight segment, then $i(t)=0$ and $F_{\text {grad }}(t)=0$. The track gradient $i=i(t)=i\left(x_{G}(t)\right)$ will be computed using the longitudinal position of the geometric centre of the vehicle $x_{G}(t)$ which is given by equation 6 .

\subsection{Driver's brake controller}

The driver's brake controller is able to mimic a standard 4-step brake controller; notch 1, 2, 3 and Emergency, corresponding to values of train brake demand of $3 \%, 6 \%, 9 \%$ and $12 \%$ of $g$ (gravitational acceleration $g=9.81 \mathrm{~m} / \mathrm{s}^{2}$ ). A brake demand subsystem in LABRADOR can generate constant and variable (pre-defined profile) values of driver brake demand.

\subsection{Wheel slide protection system (WSP)}

LABRADOR uses a simple model of WSP in which it is assumed that the WSP controller has perfect knowledge of vehicle speed. The WSP model assumes two possible positions: apply and release. These two actions are taken based on the wheel slide $s_{j}(t)$ for wheelset $j$ at a particular time $t$. Equation 25 shows that wheel slide is calculated as the ratio between the difference of vehicle $(\dot{x}(t))$ and wheelset speeds $\left(\dot{\theta}_{j}(t) . R\right)$ over the vehicle speed:

$$
s_{j}(t)=\frac{\dot{x}(t)-\dot{\theta}_{j}(t) \cdot R}{\dot{x}(t)}=1-\frac{\dot{\theta}_{j}(t) \cdot R}{\dot{x}(t)}
$$

A WSP system would then control the speed difference or wheel slide $\left(s_{j}\right)$ for each wheelset and would apply or release the brakes depending on these terms. Therefore if the wheel slide $\left(s_{j}\right)$ is greater than a certain threshold $\left(L_{Y}\right)$ for more than a certain time threshold $\left(t_{Y}\right)$, then the WSP is activated and the brakes are released, until wheel creepage $\left(s_{j}\right)$ is less than a certain threshold $\left(s_{\min }\right)$ for more than a certain time threshold $\left(t_{y d}\right)$, whereupon the WSP is deactivated and the brake is re-applied to the demanded level after a delay time. Figure 9 shows the flowchart of the WSP logic. 


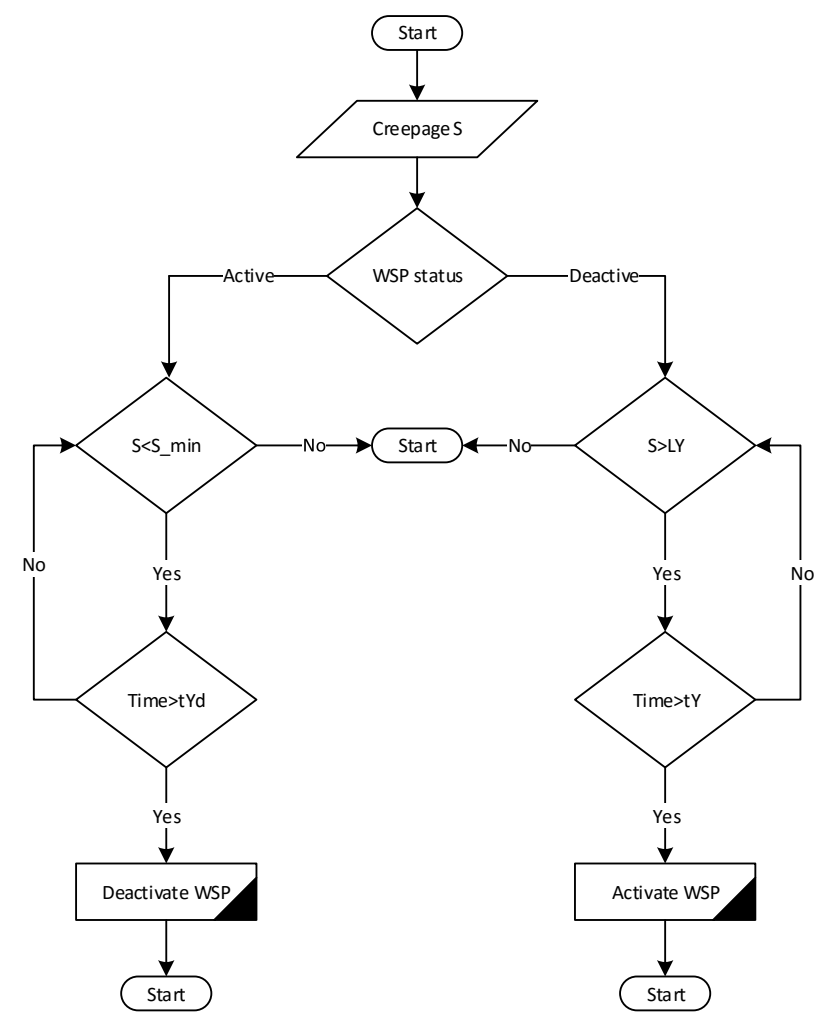

Figure 9 WSP logic flowchart

Faulty brake functionality has been also added to the wheelset subsystem where faulty means that the brake is not applied.

\subsection{Sanding system model}

The sanding model in LABRADOR uses the model that developed by Alan Lawton [12] which is based on a fixed rate of $2 \mathrm{~kg} /$ minute .

In LABRADOR models the sander is activated and deactivated based on the creepage value. For example, the sander is triggered if wheel slide is higher than a certain threshold $L_{X}$, which can be defined by the user, for a certain amount of time $t_{X}$. The sander will be deactivated as soon as the creepage value become less than a certain threshold Sand $_{s_{-} \min }$.

Figure 10 shows a flowchart illustrating the logic of this type of sander.

A simple model developed by [12] has been used to calculate the change in adhesion due to sand at each wheelset. The model is based on two parameters; adhesion boost from sand and residual sand ratio:

- Adhesion boost from sand is the adhesion increase generated at the first wheelset to pass over newly applied sand. 
- Residual sand ratio is the ratio of adhesion at one wheelset relative to adhesion at the preceding wheelset and is used to represent the diminishing effect of sand on adhesion at each successive wheel.

Both of these parameters vary with the rate at which sand is discharged. In LABRADOR a constant sanding rate of $2 \mathrm{~kg} / \mathrm{min}$ is considered in which the adhesion boost from sand is about 0.06 and the residual sand ratio is $50 \%$. However, the user can configure these values with other sanding system parameters (e.g. cut off speed, $L_{x}, t_{X}$, and $t_{S}$ ) via the GUI.

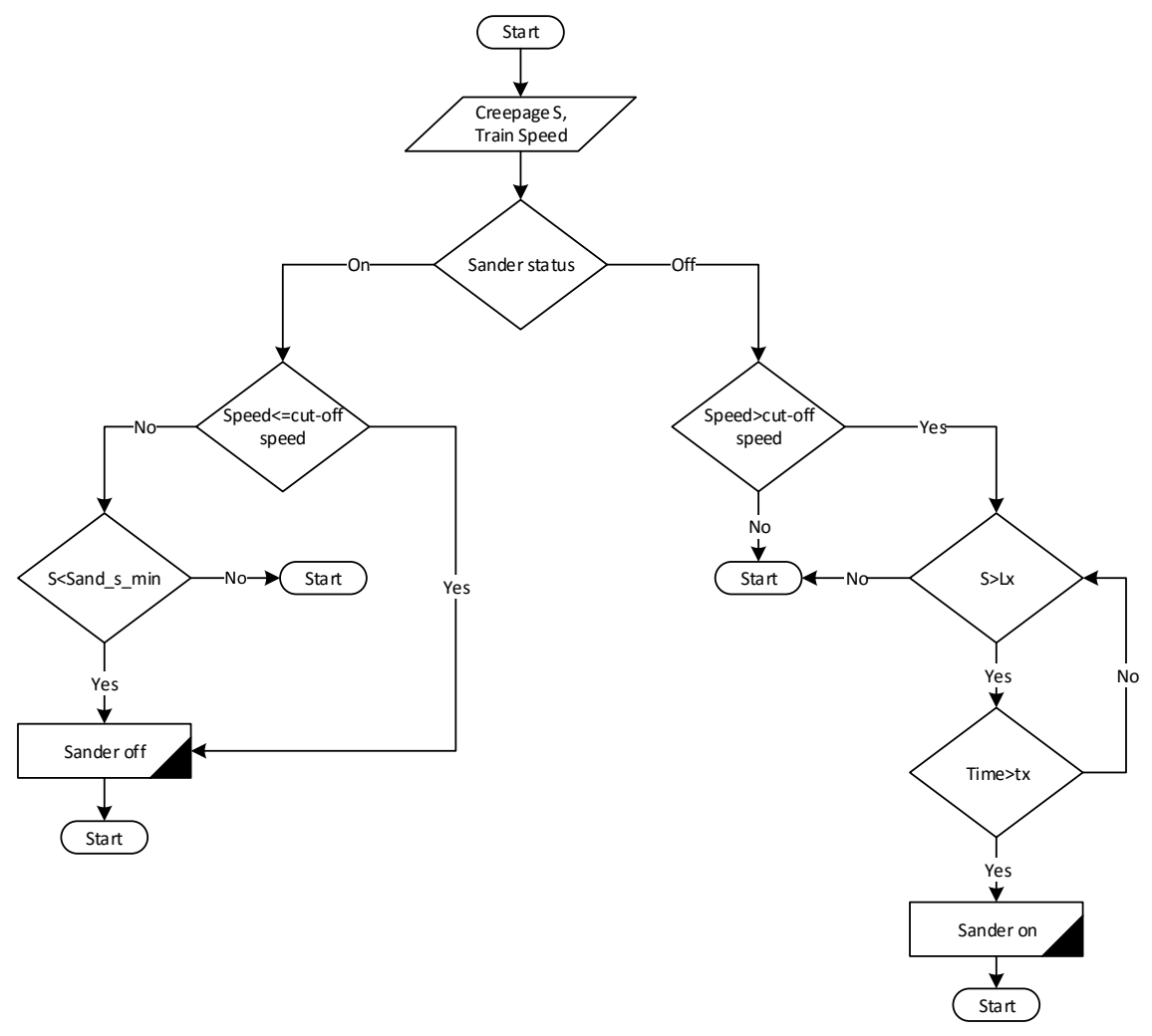

Figure 10 Sanding system operating flowchart

Figure 11 shows simulation results for a two car train operating in low adhesion conditions with a sander fitted on the third wheelset. It can be seen that when the sander is triggered the adhesion increases by the amount that equals to the maximum adhesion increment due to sanding, which is 0.06 in this case. Then the adhesion boost for the following wheelset is reduced by $50 \%$ at each wheelset. 


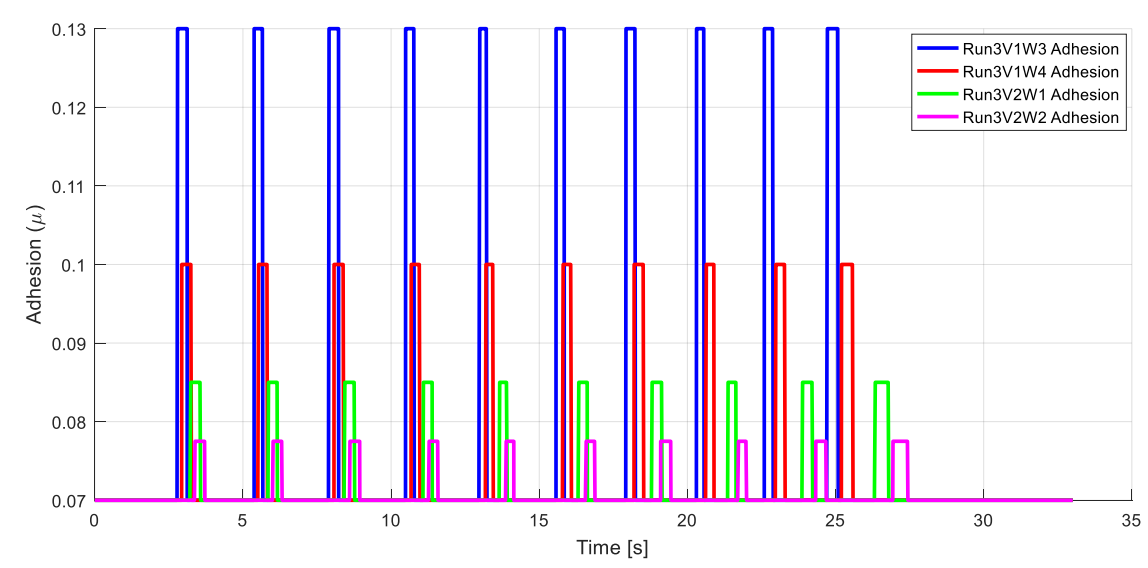

Figure 11 Adhesion boost due to sanding effect for wheelset 3 (blue), wheelset 4 (red), wheelset 5 (green), and wheelset 6 (magenta)

Figure 12 shows the effect of sanding on the wheel-rail forces for the effected wheelsets, it can be seen that the wheel-rail forces are increased when the wheelsets' adhesion is increased.

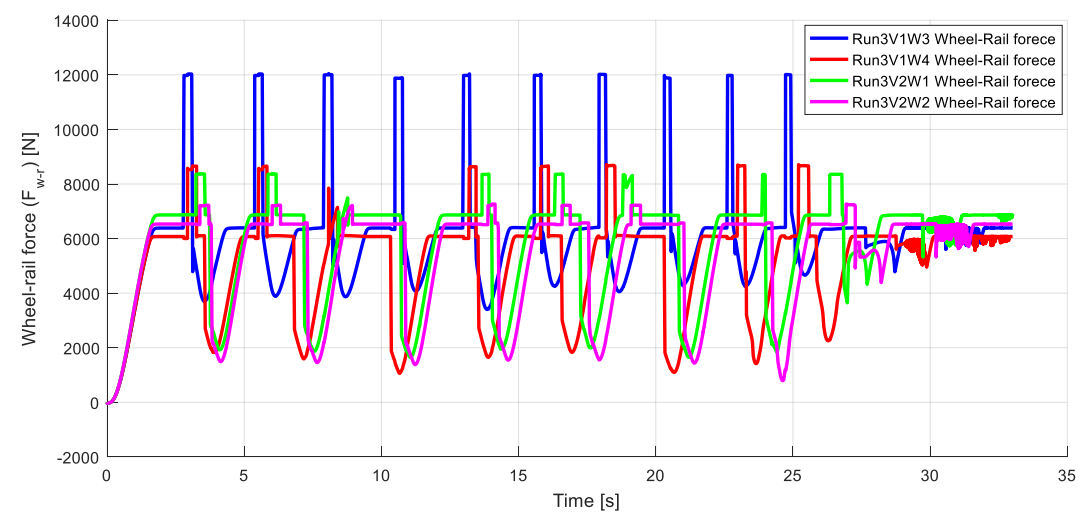

Figure 12 Wheel-rail force changes due to sanding for wheelset 3 (blue), wheelset 4 (red), wheelset 5 (green), and wheelset 6 (magenta)

\subsection{Drying effect model}

A very simple model has been used for drying effects in which wheelsets 2 , wheelset 3 , and wheelset 4 are the only wheelsets to be affected. The Wheelset 4 will get a maximum adhesion benefit while the wheelset 3 and wheelset 2 will get a half and a third of the maximum value respectively. For example, if the maximum predefined value $\left(A d_{D r y}\right)$ for the adhesion increment is $A d_{D r y}=0.15$ then the adhesion at the wheelset 2 will be increased by $0.15 / 3$, adhesion at wheelset 3 will be increased by $0.15 / 2$ and finally the adhesion at wheelset 4 will be increased by 0.15 . There is a lack of literature on the drying effects in wheel-rail contact, and there is no evidence or can be used to validate this simple model. However, the LABRADOR modular structure make it easy to modify the drying effect calculation if an improved model emerges in the future. 


\subsection{Dynamic braking and brake blending model}

According to [13], brake blending is the automatic mixture of the dynamic braking provided by the traction system and the traditional friction braking system. The dynamic brake uses the traction motors as generators, producing energy that can be dissipated in the form of heat (rheostatic braking) or fed back into the overhead line or third rail (regenerative braking). Figure 13, adapted from RSSB report T860 [14] on the benefits of all-electric braking, describes the dynamic brake effort for different speeds. Given the fade and base speeds $\left(S_{\text {fade }}\right.$ and $\left.S_{\text {base }}\right)$, three speed regions can be distinguished:

- Train speed is lower than fade speed ( $\dot{x}<S_{\text {fade }}$ ) the dynamic brake effort 'fades' linearly (decreases linearly) with speed;

- Train speed is between the fade and base speeds $\left(S_{\text {fade }} \leq \dot{x}<S_{\text {base }}\right)$, the dynamic brake effort is at most the maximum dynamic force $\left(F_{-}(\max\right.$, dynamic $\left.)\right)$, with zero brake force from other brake systems;

- Train speed is higher than base speed ( $\dot{x} \geq S_{\text {fade }}$ ), the brake effort reduces with speed squared to a minimum of $\alpha . F_{-}$(max, dynamic) when the train speed is equal to the top/design speed $\left(\dot{x}=S_{\text {top }}\right)$, in which $\alpha$ is a positive quantity that reflects the amount of the maximum braking force due to dynamic braking at the top speed.

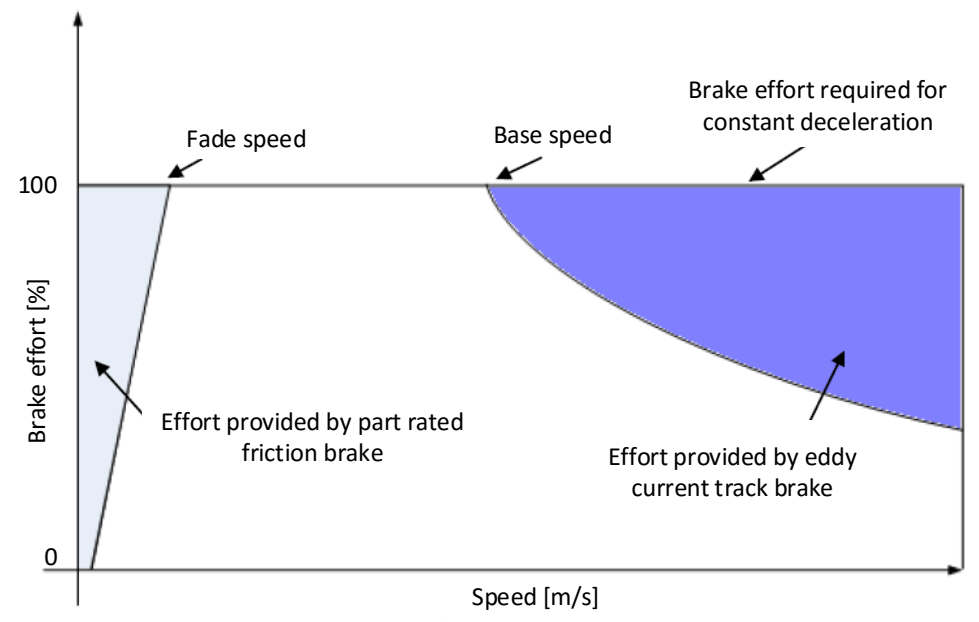

Figure 13 Typical dynamic brake effort curve (Source: T860 RSSB report (RSSB 2012)).

The distribution of brake demand into the dynamic brake demand component and the friction brake demand component depending on the train speed (or estimated train speed) can be defined by the user. It is assumed that the remaining brake effort is supplied by the friction brakes. Nevertheless, it is important to mention that this distribution of brake effort can be done locally for each motored wheelset or in more sophisticated ways (e.g. at each vehicle or at each unit). 


\subsection{Contact patch temperature model}

The contact patch temperature model was developed based on Model developed by Tanvir [15]. Tanvir's expression for the contact patch temperature due to slip in braking is given by:

$$
\theta_{w}=\theta_{r}=\frac{2.26 \times P_{m} \cdot \mu}{K}\left(\frac{a . \alpha . V}{\pi}\right)^{1 / 2}\left\{1-(1-s)^{1 / 2}\right\}
$$

Where $\theta_{w}$ and $\theta_{r}$ are the interface temperatures between the wheel and the rail respectively (which are assumed to be equal), $P_{m}$ is the maximum contact pressure, $\mu$ is the friction coefficient between the wheel and the rail, $K$ is the thermal conductivity (for steel $K=46 \mathrm{~W} \cdot \mathrm{m}^{-1} .{ }^{\circ} \mathrm{C}^{-1}$ ), $a$ is the semi-axis of the contact ellipse in the longitudinal direction, $\alpha$ is the thermal diffusivity (for steel $\alpha=0.12 \times$ $\left.10^{-4} \mathrm{~m}^{2} \cdot \mathrm{s}^{-1}\right), V$ is the vehicle speed and $s$ is the slip ratio (creepage):

$$
s=\frac{v_{s}}{V}=\frac{\left(v_{w}-V\right)}{V}
$$

where $v_{S}$ is the slip speed that is the difference between the wheel speed and the vehicle speed.

Note that the maximum pressure $P_{m}$ depends on the normal load $(N)$ and semi-axis dimensions of the contact patch ( $a$ and $b$ ) and can be computed as:

$$
P_{m}=\frac{3 . N}{2 \pi a b}
$$

\subsection{Weight transfer model}

The Weight transfer is the effect whereby the axle loads of a vehicle change as the vehicle is accelerated, decelerated, or travels on a gradient. For example, when brakes are applied the vehicle decelerates hence the leading bogie will see an increase load and the trailer bogie will see reduced load. The amount of load transfer depends on the deceleration value (i.e. the greater the deceleration, the greater the change in axle loads). However, the weight transfer effect for an individual bogie will depend on the location of the body/bogie pivot. The load transfer model is given by equations (29-32):

$$
\begin{aligned}
Q_{1}=\left[\frac{M_{1} j}{a+b}+\right. & \left.\frac{M_{b} h(m-b)}{(a+b)(x+y)}\right] A+\frac{i+j}{a+b}\left(F_{1}+F_{2}\right)+\left[\frac{M_{1} g b}{a+b}+\frac{M_{b} g y(b-m)}{(a+b)(x+y)}\right] \cos (\theta) \\
& +\left[\frac{M_{1} g j}{a+b}+\frac{M_{b} g(m-b)}{(a+b)(x+y)}\right] \sin (\theta)
\end{aligned}
$$




$$
\begin{aligned}
Q_{2}=-\left[\frac{M_{1} j}{a+b}+\right. & \left.\frac{M_{b} h(a+m)}{(a+b)(x+y)}\right] A-\frac{i+j}{a+b}\left(F_{1}+F_{2}\right) \\
& +\left[\frac{M_{1} g a}{a+b}+\frac{M_{b} g y(a+m)}{(a+b)(x+y)}\right] \cos (\theta)+\left[-\frac{M_{1} g j}{a+b}-\frac{M_{b} g(a+m)}{(a+b)(x+y)}\right] \sin (\theta) \\
Q_{3}=\left[\frac{M_{2} k}{c+d}+\right. & \left.\frac{M_{b} h(d+n)}{(c+d)(x+y)}\right] A+\frac{k+l}{c+d}\left(F_{3}+F_{4}\right)+\left[\frac{M_{2} g d}{c+d}+\frac{M_{b} g y(d+n)}{(c+d)(x+y)}\right] \cos (\theta) \\
& +\left[\frac{M_{2} g k}{c+d}+\frac{M_{b} g(d+n)}{(c+d)(x+y)}\right] \sin (\theta) \\
Q_{4}=\left[-\frac{M_{2} k}{c+d}+\right. & \left.\frac{M_{b} h(c-n)}{(c+d)(x+y)}\right] A-\frac{k+l}{c+d}\left(F_{3}+F_{4}\right) \\
& +\left[\frac{M_{2} g c}{c+d}+\frac{M_{b} g x(c-n)}{(c+d)(x+y)}\right] \cos (\theta)+\left[-\frac{M_{2} g k}{c+d}+\frac{M_{b} g(c-n)}{(c+d)(x+y)}\right] \sin (\theta)
\end{aligned}
$$

Where:

$Q_{1}, Q_{2}, Q_{3}$, and $Q_{4}[N]$ : Wheelset 1 , wheelset 2, wheelset 3, and wheelset 4 load respectively.

$F_{1}, F_{2}, F_{3}$, and $F_{4}[N]$ : The wheel-rail forces at wheelset 1 , wheelset 2 , wheelset 3 , and wheelset 4 load respectively. $M_{1}$ and $M_{2}[\mathrm{~kg}]$ : Bogie 1 and bogie 2 masses respectively. $M_{b}[\mathrm{~kg}]$ : Vehicle body mass. $\theta[\mathrm{rad}]$ : Track gradient. $x[\mathrm{~m}]$ : Horizontal distance from body centre of gravity to bogie 1 pivot. $y[m]$ : Horizontal distance from body centre of gravity to bogie 2 pivot. $i[m]$ : Height of bogie 1 centre of gravity above rail level. $l[m]$ : Height of bogie 2 centre of gravity above rail level.

$j[m]$ : Height of bogie 1 pivot above bogie 1 centre of gravity. $k[m]$ : Height of bogie 2 pivot above bogie 2 centre of gravity. $h[m]$ : Height of the body centre of gravity above bogie's pivot. $a[m]$ : Horizontal distance from wheelset 1 contact to bogie 1 centre of gravity. $b[m]$ : Horizontal distance from wheelset 2 contact to bogie 1 centre of gravity. $c[m]$ : Horizontal distance from wheelset 3 contact to bogie 2 centre of gravity. $d[m]$ : Horizontal distance from wheelset 4 contact to bogie 2 centre of gravity. $m[m]$ : Horizontal distance of bogie 1 centre of gravity outboard of bogie 1 pivot. $n[m]$ : Horizontal distance of bogie 2 centre of gravity outboard of bogie 2 pivot.

The acceleration $\mathrm{A}$ is calculated based on forces, masses, and the gradient:

$$
A=\frac{-\left(F_{1}+F_{2}\right)-\left(F_{3}+F_{4}\right)-\left(M_{b}+M_{1}+M_{2}\right) g \sin (\theta)}{M_{1}+M_{2}+M_{b}}
$$

Figure 14 shows the Simulink block diagram of the load transfer model which is used in LABRADOR. 
Figure 15 shows simulation results of the effect of the load transfer model on wheelsets' loads for a single vehicle train during braking in low adhesion conditions. The simulation results show that the load on the first and third wheelsets, which are the leading wheelset in the leading and trailing bogies respectively, increased as the train decelerates while the second and fourth wheelsets loads are decreased. However, as the load transfer model takes into account the load transfer from car body and bogie frame the total load of the first and second wheelsets is greater than the total load of the third and fourth wheelset due to the effect of the car body load transfer. Figure 16 shows the train acceleration, it can be seen that the acceleration fluctuation due to WSP and sanding systems activity (shown in Figure 17) is reflected directly in the wheelsets' load. The spikes in load in wheelset three and four are due to change in wheel-rail forces $\left(F_{3}, F_{4}\right)$ when the sander (at the third wheelset) is activated. Although the first and second wheelsets do not benefit from sand an effect on their load can be seen as small spikes in load. The effect of sanding on the first and second wheelsets' load results from the acceleration which is effected by the changes of the forces $\left(F_{3}, F_{4}\right)$.

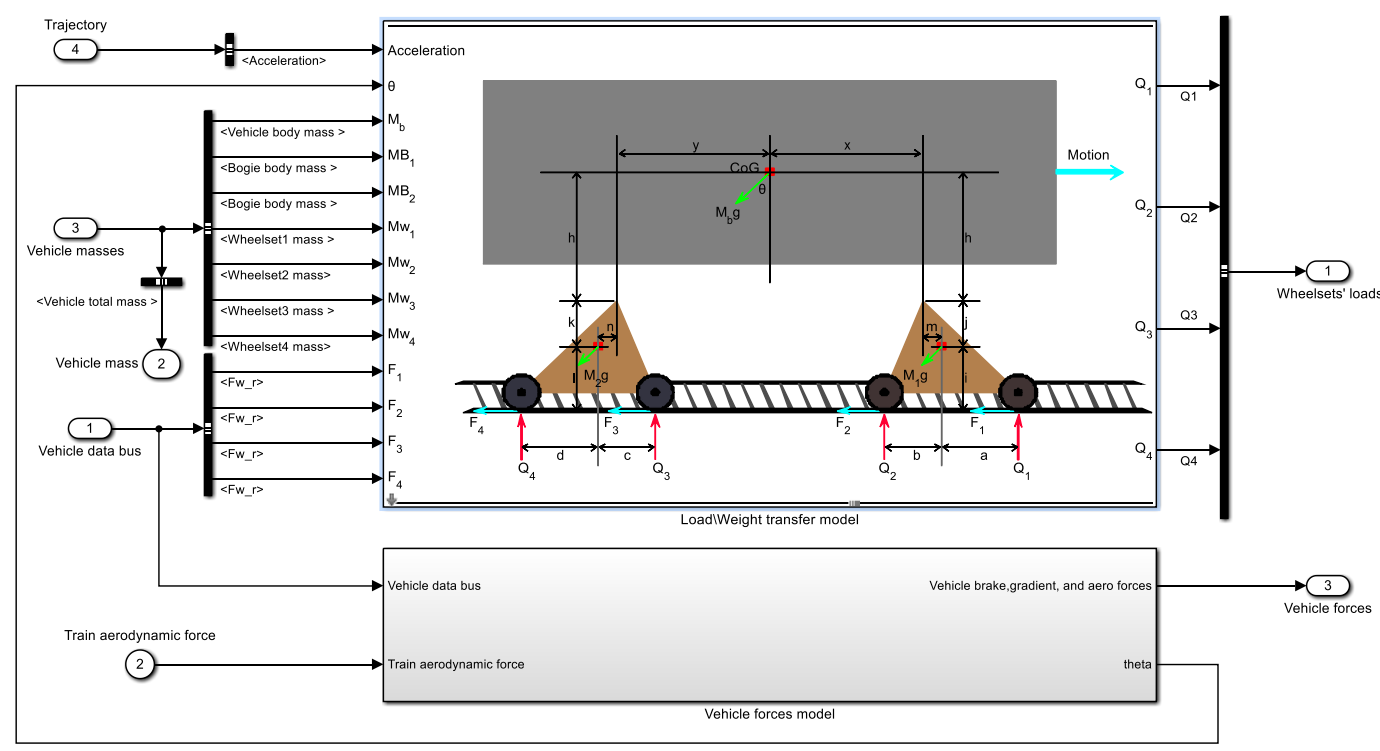

Figure 14 Simulink block diagram of load transfer model

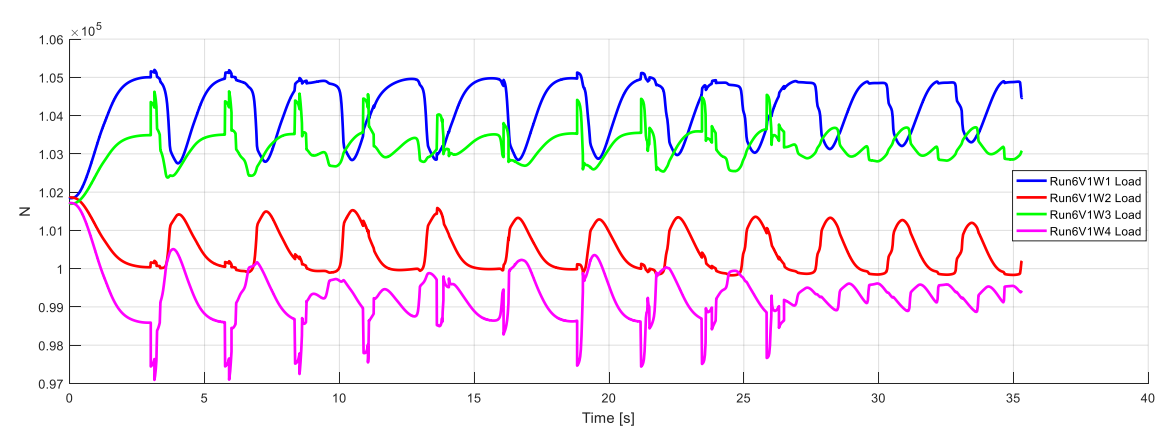

Figure 15 Simulated wheelset loads for a single car train model during braking in low adhesion conditions. Wheelset1 (blue), whelset2 (red), wheelset3 (green), and wheelset4 (magenta) 


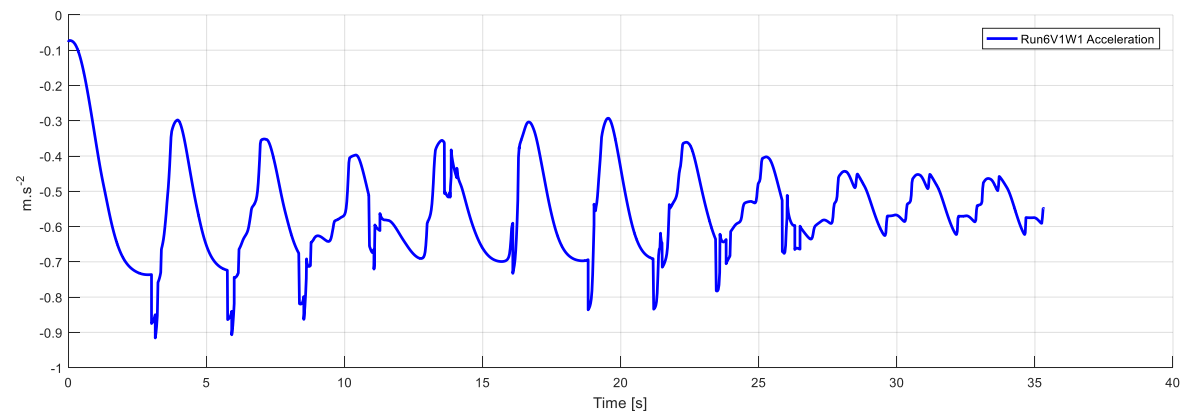

Figure 16 Simulated acceleration for single car model braking under low adhesion conditions

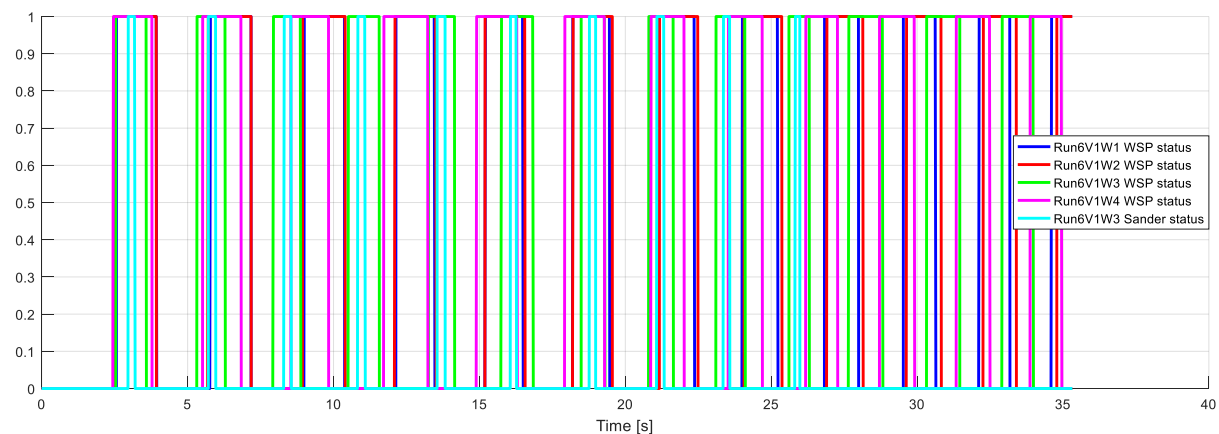

Figure 17 WSPs' status for wheelset1 (blue), whelset2 (red), wheelset3 (green), and wheelset4 (magenta) and wheelset3 sander status (cyan) of single car train model

\section{Model validation}

This is a limited validation based on historic brake tests under 'high' adhesion conditions (i.e. no wheel slide) reported by BR in 1991 [16] [17] [18] [19]. However, more detailed validation under low adhesion conditions has not been carried out in this stage of the project due to two main challenges; firstly, there is not enough test data at low adhesion conditions, and secondly, the ability to model modern WSPs is limited due to the commercial confidentiality of the modern WSPs. The next section discusses validation process for high adhesion condition using some test data for class 153 and class 158 trains.

\section{Class 153}

A series of on-track braking tests are reported in [16] for a single car class 153 diesel unit. Each test involves measuring the stopping distance from different speeds. These tests were then repeated with the vehicle in the crush laden condition (involving an increase of the vehicle mass by $13,600 \mathrm{~kg}$, from $M=41,200 \mathrm{~kg}$ to $M=54,800 \mathrm{~kg}$ ).

Several simulations were run with different initial braking speeds and using the full Polach model for dry conditions. All the simulation results are plotted in Figure 18 and they are compared with 
experimental tests from report [16]. It can be seen that at low speeds there is a good match between predicted performance and practice. However, for higher speeds, the LABRADOR model underestimates the braking distance for the tread braked class 153. Whilst this might be due to the fact that the pneumatic system is not being directly modelled in LABRADOR, a plausible explanation is that that tread brakes are more susceptible to brake fade (due to heating of the blocks) on stops from higher speeds. The next section shows experimental and simulation tests for a disc braked class 158 .

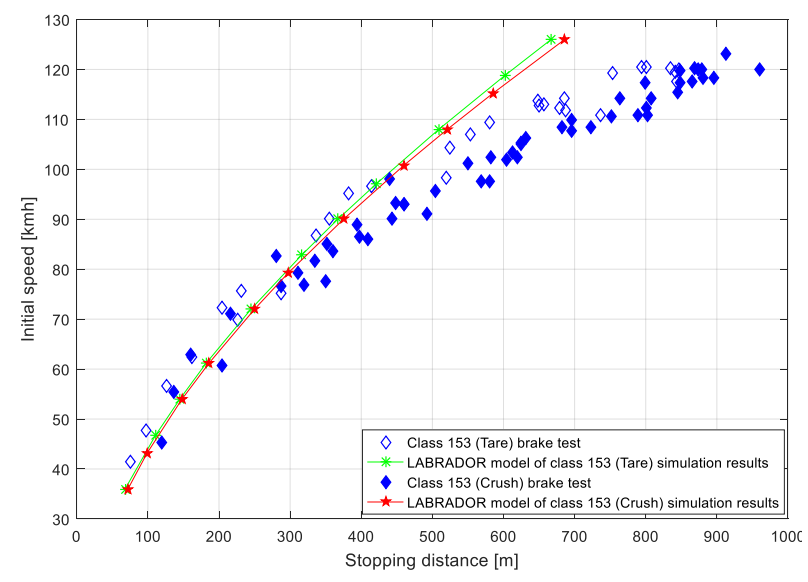

Figure 18 Comparison between data from experimental tests (dry), full service brake application (NOTCH 3) in tare and crush load condition and simulations from LABRADOR single vehicle braking model for different initial speed

\section{Class 158}

The class 158s are disc braked DMUs with a maximum speed of $90 \mathrm{mph}$. Figure 19 provides a schematic diagram of a 2-car class 158 unit

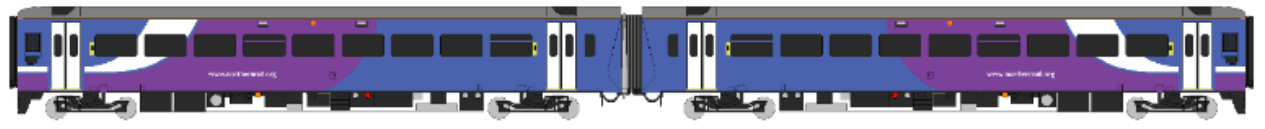

Figure 19 Schematic diagram of a 2-car class 158 unit (DMS-DMS)

A series of on track braking tests are reported in BR reports [17] [18] [19] for a 2-car class 158 diesel multiple unit. The train in reports $1159 \mathrm{C}$ and $1159 \mathrm{~K}$ was equipped with FERODO 3204 brake pads while report 1159M gives braking test for three types of braking pad materials; FERODO 3204/3, FERODO 3204/F, and ID 425.

Simulation results for the LABRADOR Class 158 model (in dry conditions) are compared with the experimental tests (also in dry conditions) in Figure 20 for tare load condition, and Figure 21 for crush laden conditions. It can be seen that LABRADOR simulation results of Class 158 show a much better fit with the experimental data (Figure 20 and Figure 21) than the simulation results for Class 153s (Figure 
18). Comparisons of the relationship between pad friction and temperature for these brake pads show much less variability than for the brake block material used on class $153 \mathrm{~s}$.

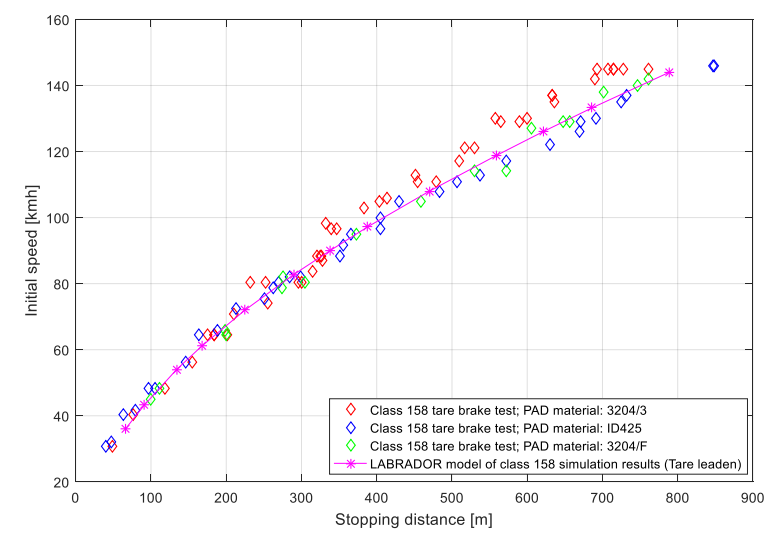

Figure 20 Comparison between experimental tests for class 158 for full service brake application in tare condition and simulations from LABRADOR model.

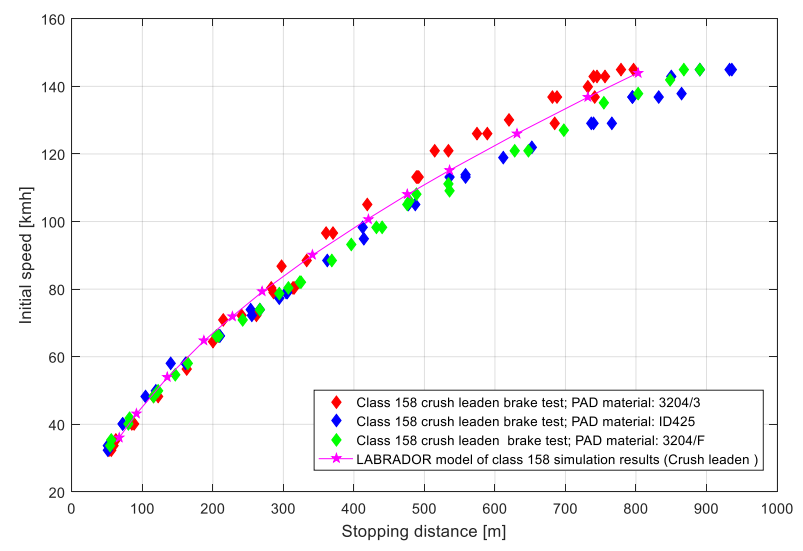

Figure 21 Comparison between experimental tests for class 158 for full service brake application in crush laden and simulations from LABRADOR model

The Class 158s in these tests were fitted with FERODO type 3204 brake pads with the following characteristics [20]:

1. The mean friction increases (slightly) as the train speed increased as shown in Figure 23 , this might be a reason of why the experimental stopping distances when using 3204 pad are slightly less than the simulation result in (Figure 20 and Figure 21).

2. The mean friction is constant with variable specific contact pressure as shown in Figure 24.

3. Figure 25 shows the relationship between the temperature and the mean friction of the $3204 / 3 \mathrm{~F}$ pad. It can be seen that below $\left(200^{\circ} \mathrm{C}\right)$ the mean friction increases with temperature. However, for temperatures above $200{ }^{\circ} \mathrm{C}$ the mean friction starts decreasing with increasing temperature. 


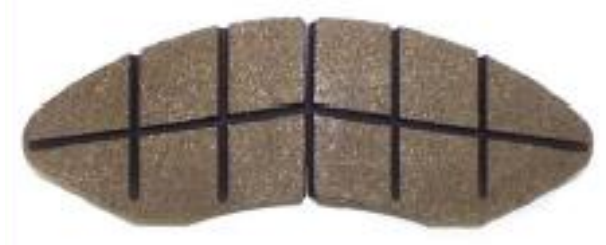

Figure 22 FERODO 3204/3F PAD used in class 158 trains [20]

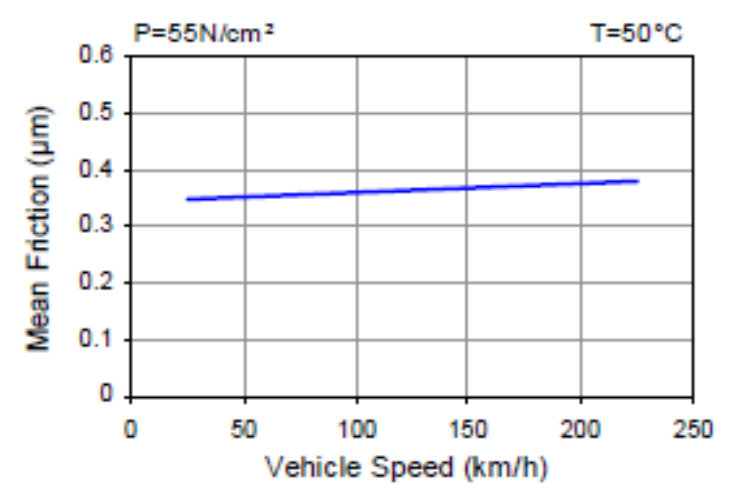

Figure 23 Mean friction vs vehicle speed of friction material 3204F [20]

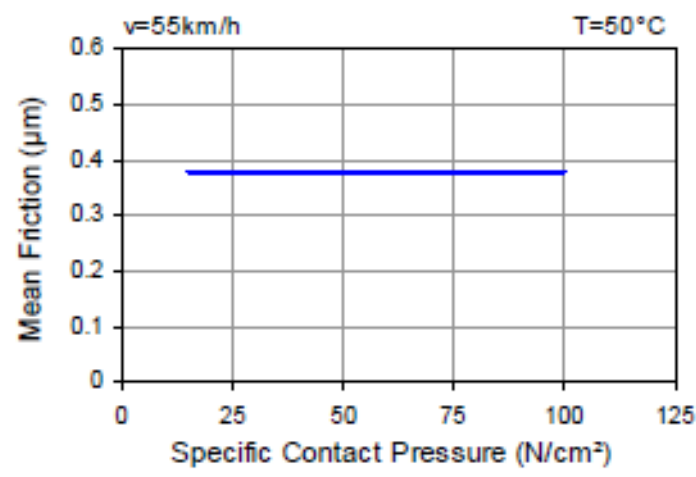

Figure 24 Mean friction vs specific contact pressure of friction material 3204F [20]

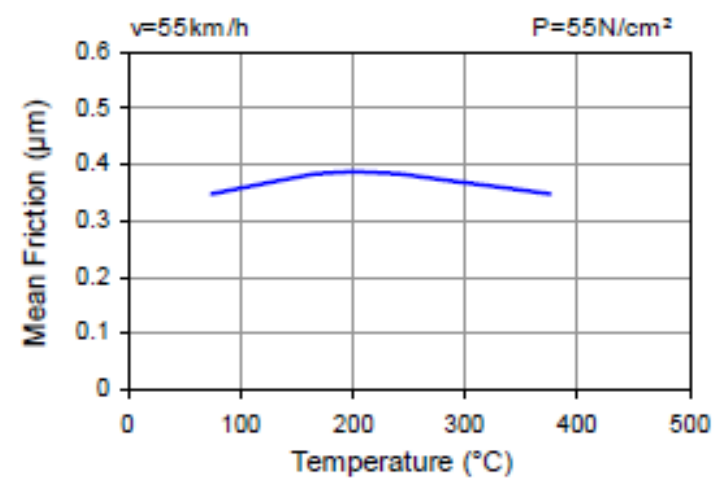

Figure 25 Mean friction vs temperature of friction material 3204F [20] 


\section{Graphical User Interface (GUI)}

The LABRADOR model allows the user to define the parameters of the different modules by using a Graphical User Interface (GUI), allowing manual configuration of vehicle, train, environment, and simulation specific inputs, through a set of menus, toolbars, push-buttons and list boxes. Input screens contain default data values in order to minimise the time required for model set-up. Inputs are grouped in panels as seen in Figure 26.

- Train profile panel: to select the train type (number of vehicles), then to set vehicles' mass profile, vehicles' geometry profile and train aerodynamic resistance profile.

- WSP and brake system panel: to set the characteristic of the vehicles' WSP systems (enable/disable, type, parameters), this panel also enables the user to simulate a brake failure at any chosen wheelset.

- Adhesion profile panel: to set adhesion profile (Simple or full Polach model).

- Gradient profile panel: to set the gradient profile (constant gradient or predefined profile).

- Sanding system panel: to set and configure sanders at each wheelset (enable, disable, type, and sanding system parameter configuration).

- Dynamic braking panel: to set and configure dynamic braking functionalities (enable/disable, dynamic braking type, and brake blending mode)

- Simulation setting pushbutton: to set the driver brake demand profile, sampling time, track length, initial speed, and pneumatic time delay.

The simulation will run and all outputs are stored and made available for the user to analyse, display and to compare with other simulation runs. Outputs can be presented by using set of flexible figures. The maximum number of figures on the GUI is four. However, users can generate as many figures as they want by selecting a figure and clicking 'maximise' repeatedly to generate as many figures as required. The output variable can be plotted against time, distance and wheelset position. The $x$-axes can be set by simply selecting one of three radio buttons as seen in Figure 26. 


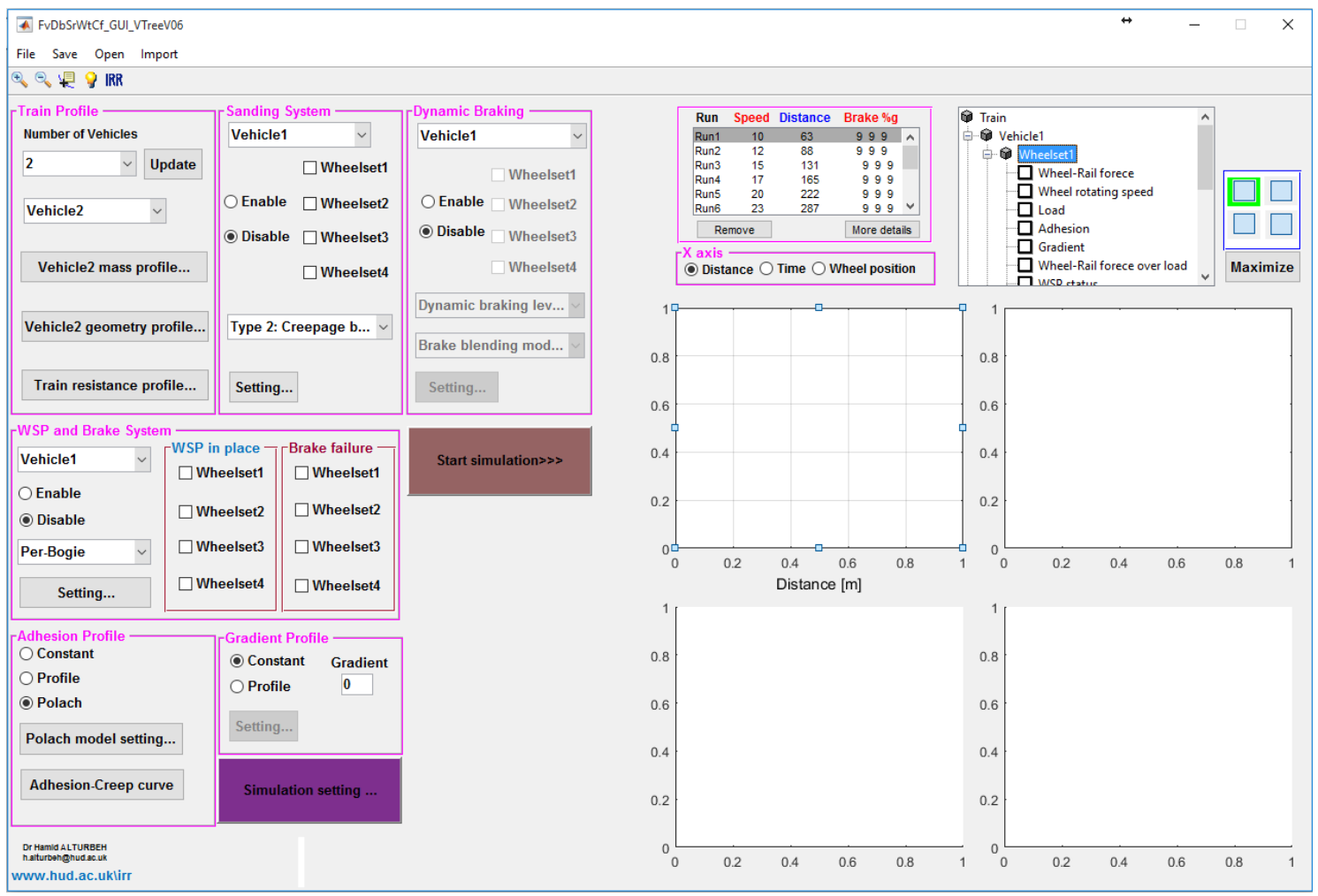

Figure 26 LABRADOR Graphical User Interface (GUI)

The generated and stored outputs include train speed, train acceleration, and the following variables for each wheelset:

- Wheel-rail force

- Wheel rotational speed

- Load

- Adhesion

- Gradient

- Wheel-rail force/Load

- WSP status

- $\quad$ Sander status

- Creepage

- Contact patch temperature

- Friction brake demand

- Dynamic brake demand

\section{Conclusion}

The LABRADOR train braking model provides a basis for simulation and assessment of alternative braking system configurations for different trains under varying track gradient and adhesion profiles. 
The model is configured to preserve the modularity of the various sub-systems within the braking system. Each sub-system is modelled separately in MATLAB/SIMULINK. This approach enables the model to be extended to represent longer trains and also to model the various brake system architectures present in older, contemporary and future rolling stock. LABRADOR will allow the study of specific brake control features such as WSP strategies, sanding effectiveness, dynamic brake utilisation, traction performance, etc. This understanding will help train operators, maintainers and integrators to optimise the braking performance of their trains.

However, further work is needed to improve the current version of LABRADOR model. Some recommendations for future work include:

- The LABRADOR model should be developed to include more sophisticated WSP models. This may be difficult due to the commercial confidentiality issues surrounding the latest WSP systems. It may be necessary to use a Hardware-in-the-Loop (HiL) approach to allow a real WSP rack to be run as part of the model, avoiding the need for a software model of the WSP functionality.

- Brake fade can affect the brake performance at high speed, thus a further development of LABRADOR model to include the brake disc temperature and pad material characteristic is recommended. This would give the user the ability to select the type of brake pad and simulate its effect on the train braking performance.

- The current drying effect is based on a very simple model. Drying and sanding effects are generally an under-researched area so a further effort is needed to improve the ability to model these effects.

\section{Acknowledgements}

The LABRADOR project has been undertaken as part of the Strategic Partnership between RSSB and the University of Huddersfield. The authors would like to thank the industry members of the project steering group which has provided advice, guidance and practical support for this project.

\section{References}

[1] L. Buckley-Johnstone, R. Lewis, K. Six and G. Trummer, "Modelling and quantifying the influence of water on wheel/rail adhesion levels," RSSB, 2016.

[2] ORE, "Adhesion during Braking and Anti-skid Devices, ORE B 164, RP 1, Synthesis of Current knowledge concerning adhesion,", Office for Research and Experiments of the International Union of Railways, Utrecht, 1985. 
[3] ORE, "Summary of theoretical and practical knowledge of poor adhesion conditions acquired since publication of B 164/RP 2," Office for Research and Experiments of the International Union of Railways, Utrecht, 1992.

[4] RSSB, " Review of Low Adhesion Research - Final report (T354).," RSSB, London, 2004.

[5] RSSB, “ Benefits of all-electric braking. Final Report (T860).," RSSB, London, 2012.

[6] L. Pugi, M. Malvezzi, S. Papini and G. Vettori, "Design and preliminary validation of a tool for the simulation of train braking performance," Journal of Modern Transportation, vol. 21, no. 4, pp. 247-257, 2013.

[7] O. Polach, "Creep forces in simulations of traction vehicles running on adhesion limit," Wear, pp. 992-1000, 2005.

[8] J. J. Kalker, "A fast agorrithm for the simplified theory of rolling contact," Vehicle System Dynamic, pp. 1-13, 1982.

[9] W. J. Davis Jr., "The Tractive Resistance of Electric Locomotives and Cars," General Electric Review, vol. 29, no. 10, pp. 685-708, 1926.

[10] B. P. Rochard and F. Schmid, "A review of methods to measure and calculate train resistances.," Proceedings of the Institution of Mechanical Engineers, Part F: Journal of Rail and Rapid Transit, pp. 185-199, 2000.

[11] D. S. Armstrong and P. Swift, "Lower energy technology. Part A, identification of energy use in multiple units. Report MR VS 077,", British Rail Research, Derby, 1990.

[12] RSSB, "Understanding the current use of sanders on multiple units (T796). Final report and Appendices," RSSB, 2010.

[13] A. Lawton, "The Effect of Sanders in Improving Train Braking Performance When Adhesion is Low," in The Sephenson Conference: Research for Railways, London, 2017.

[14] A. L. Nicholas, "Braking systems and their control architectures," in IET Professional Development Course on Electric Traction Systems , London, 2012.

[15] RSSB, "Benefits of all-electric braking, Final Report (T860)," 2012. 
[16] M. A. Tanvir, "Temperature rise due to slip between wheel and rail- an analytical solution for Hertzian contact.," Wear, pp. 295-308, 1980.

[17] BR, "British Rail Report No. 1278G - Class 153 Type tests - Braking performance.," BR, 1991.

[18] BR, " British Rail Report No. 1159C - Class 158 Type tests - Full Service Braking performance of unit 158701 tare, seated and crush laden.," BR, 1991.

[19] BR, "British Rail Report No. 1159K - Class 158 Type tests - Full Service Braking performance and holding capacity of step 1 brake on unit 748.," BR, 1991.

[20] BR, " British Rail Report No. 1159M - Class 158 Brake Tests - Full Service Braking of unit 797 with alternative friction materials.," BR, 1991.

[21] FERODO, "Technical Data Sheet of FERODO 3204/3F," Federal Mogul, 2017. 